This document is the accepted manuscript version of the following article:

Ferrari, B. J. D., Vignati, D. A. L., Roulier, J. L., Coquery, M., Szalinska, E., Bobrowski, A., ... Dominik, J. (2019). Chromium bioavailability in aquatic systems impacted by tannery wastewaters. Part 2: new insights from laboratory and in situ testing with Chironomus riparius Meigen (Diptera, Chironomidae). Science of the Total Environment, 653, 1-9. https://doi.org/10.1016/j.scitotenv.2018.10.258

This manuscript version is made available under the CC-BY-NC-ND 4.0 license http://creativecommons.org/licenses/by-nc-nd/4.0/

Chromium bioavailability in aquatic systems impacted by tannery wastewaters. Part 2:

new insights from laboratory and in situ testing with Chironomus riparius Meigen

\title{
(Diptera, Chironomidae)
}

(1)

Published in Science of the Total Environment, doi:

https://doi.org/10.1016/i.scitotenv.2018.10.258

Ferrari B.J.D., ${ }^{\mathrm{a}, \mathrm{b}}$, Vignati D.AL. ${ }^{\mathrm{a}, \mathrm{c}}$, Roulier J.-L. ${ }^{\mathrm{d}}$, Coquery M. ${ }^{\mathrm{d}}$, Szalinska E. ${ }^{\mathrm{e}}$, Bobrowski A. Czaplicka A. ${ }^{\mathrm{g}}$, Dominik, J.,

a) Department F.-A. Forel for Environmental and Aquatic Sciences, University of Geneva, Uni Carl Vogt, 66 boulevard Carl-Vogt CH-1211 Geneva, Switzerland

b) Swiss Centre for Applied Ecotoxicology Eawag-EPFL (Centre Ecotox), EPFL-ENACIIE-GE, Station 2, 1015 Lausanne, Switzerland

c) Université de Lorraine, CNRS, LIEC, F-57000 Metz, France

d) Irstea, UR RiverLy, centre de Lyon-Villeurbanne, F-69625 Villeurbanne, France

e) Department of Environment Protection, Faculty of Geology, Geophysics and Environmental Protection, AGH University of Science and Technology, 30 A. Mickiewicza Av. , 30-059 Krakow, Poland. 
f) Department of Building Materials Technology Faculty of Materials Science and Ceramics, AGH University of Science and Technology, 30 A. Mickiewicza Av. , 30-059 Krakow, Poland

g) Department of Water Supply, Sewerage and Environmental Monitoring, Cracow University of Technology, 24 Warszawska ul., 31-155 Krakow, Poland

h) Institute of Marine Science - National Research Council (ISMAR-CNR) Arsenale - Tesa 104, Castello 2737/F, 30122 Venice, Italy

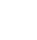

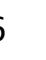

37

8

9

45 7

\section{8} 9 50 


\section{Abstract}

Chromium is widely used as a tanning agent and can become a contaminant of concern in aquatic ecosystems receiving discharges from industrial or artisanal tanning activities. In a companion study, we showed that $\mathrm{Cr}$ discharged by tanneries was bioavailable to indigenous chironomids with accumulation via sediment ingestion likely to represent the predominant exposure route. However, $\mathrm{Cr}$ accumulation by chironomids did not directly reflect the degree of sediment contamination and the potential adverse effects of $\mathrm{Cr}$ accumulation on chironomids were not evaluated. In the present study, chironomids were exposed to homogenised, field-collected sediments in the laboratory and to intact sediments in situ using a customised caging system. Chromium concentrations were assessed in sediments, exposed larvae of laboratory-reared Chironomus riparius and overlying waters of in situ cages.

Experimental results of $\mathrm{Cr}$ bioaccumulation were compared with expected $\mathrm{Cr}$ body burden in chironomids calculated using biodynamic modelling. Our data provided strong support to the hypothesis that $\mathrm{Cr}$ bioaccumulation in the field is specifically controlled by the deposition of contaminated suspended particulate matter (SPM) containing a pool of Cr readily bioavailable to surface deposit feeders. Considering freshly deposited SPM as an additional route of exposure for surface deposit feeders leads to a good agreement between the modelling and experimental results. Additionally, a Cr body burden of about $77 \mu \mathrm{g} \mathrm{g}^{-1} \mathrm{~d}$.w was identified as a tentative threshold above which effects on the growth of $C$. riparius may appear. While both laboratory and in situ experiments provide evidence for the availability of $\mathrm{Cr}$ in aquatic system impacted by tannery wastewaters, standard laboratory exposure conditions may miss additional exposure routes in the field and underestimate possible adverse effects on benthic organisms.

Keywords. Chironomids; Bioaccumulation; Suspended matter; Body residue; Sediment; Reservoir 


\section{Introduction}

Bioaccumulation and toxicity of trace elements strongly depend on their speciation and on the actual exposure conditions experienced by target organisms; e.g. continuous $v s$. discontinuous inputs, contaminant uptake via different exposure routes (water vs. food), biological traits (e.g. feeding habit, respiration, growth, reproduction) of the species of interest (Fairbrother et al., 2007). Standardized laboratory experiments cannot account for all these factors although their importance is well-recognized and their predictive ability can be improved by a careful characterization of the actual exposure conditions in the selected laboratory settings (Simpson and Batley, 2007). Similarly, pulse and chase experiments using radiolabelled elements allow the study of the relative importance of different exposure routes, notably water exposure vs. food ingestion, in a variety of organisms (Baumann and Fisher, 2011; Wang et al., 1997), but cannot reproduce the complex array of environmental factors that influences bioavailability and toxicity in situ. To address these problems, the scientific community has engaged in actively developing tools to narrow the gap between laboratory and field studies. At present, microcosm and in situ techniques are sufficiently mature and versatile to be of use as supporting studies in tiered risk assessment procedures (Burton Jr et al., 2012; Crane et al., 2007; Ferrari and Faburé, 2017; Ferrari et al., 2014). An appropriate integration between laboratory and in situ approaches can help to better understand the bioavailability and toxicity of specific contaminants in ecosystems impacted by complex mixtures of contaminants such as tannery effluents (Vignati et al., 2007).

Adverse biological effects on aquatic organism in tannery contaminated systems are well documented (Khwaja et al., 2001; Koukal et al., 2004; Leghouchi et al., 2009). However, tannery effluents have a very complex composition and specifically ascribing the observed effects to $\mathrm{Cr}$, typically used as a tanning agent in its trivalent form, remains difficult. Understanding of Cr bioavailability and toxicity in the field is further complicated by the 
possible simultaneous presence of trivalent and hexavalent $\mathrm{Cr}$ forms that are characterized by different environmental mobility and toxicity (Vignati et al., this issue). On the other hand, Michailova et al. (2011) showed a genotoxic response in chironomids growing in a tanneryimpacted system (the Dunajec river, southern Poland), where $\mathrm{Cr}$ and $\mathrm{Cd}$ were the only trace elements of concern. Although genotoxic and cancerogenic effects are mostly attributed to Cr(VI) exposure ((De Flora et al., 1990), genotoxic effects of Cr(III) organic compounds were also observed, along with changes in DNA and protein levels, in the yeast Saccharomyces cerevisiae (Chatterjee and Luo, 2010). The number of studies documenting a high toxicity of $\mathrm{Cr}$ (III) in standard laboratory settings is also increasing (Aharchaou et al., 2018; BencheikhLatmani et al., 2007; Kováčik et al., 2015; Ponti et al., 2014; Vignati et al., 2010), suggesting that $\mathrm{Cr}(\mathrm{III})$ is less harmless than admitted by the current scientific consensus. Significant polytene chromosome aberrations were found in Chironomus riparius exposed to $\mathrm{Cr}(\mathrm{III})$ contaminated sediments in laboratory conditions (Michailova et al., 2001).

In part 1 of the present study (Vignati et al., this issue), we showed that $\mathrm{Cr}$ discharged by tanneries is bioavailable to chironomids, but that the accumulation patterns do not simply reflect the contamination in abiotic matrices. By combining laboratory tests and in situ studies with caged, transplanted larvae of the model species Chironomus riparius Meigen (Diptera, Chironomidae), we specifically tested: a) if bioaccumulation in the field can be controlled by the ingestion of freshly-deposited contaminated SPM containing a pool of $\mathrm{Cr}$ readily bioavailable to surface deposit feeders such as chironomids and, b) at which level $\mathrm{Cr}$ accumulation may have adverse effects on the growth of $C$. riparius.

\section{Material and Methods}

2.1 Model organisms and study area 
The non-biting midge larvae Chironomus riparius were used as model species for all experiments. This species is commonly used for ecotoxicological purposes, can be reared in laboratory conditions and has easily measurable and well modelled life-cycle traits. Chironomus riparius has been considered as a model organism in several internationally validated guidelines for assessing the toxicity of chemicals and for evaluating the quality of natural sediments (see Ferrari et al. 2017 and references therein).

Larvae used in the tests originated from a culture maintained in our laboratory. The culture was started from egg masses kindly provided by Dr. J. Garric (Irstea, formerly Cemagref, Lyon, France). The methods for maintaining the culture and preparing the organisms for experiments are detailed in Ferrari et al. (2014). For this study, two kinds of experiments were conducted, either by starting with young second instar larvae (7-day laboratory tests) or by starting with young fourth instar larvae (4-day laboratory and in situ tests). The larval stages were determined by checking the length of the larvae and by controlling on few specimens the head capsule width. Each set of experiment was designed to allow assessment of bioaccumulation of $\mathrm{Cr}$, but the toxicity of the whole sediment on chironomids (growth and survival) was recorded at the same time. The chronological steps for implementing the tests are depicted in Figure S1.

In situ exposure and sample collection for the concomitant laboratory experiments were carried out in the Czorsztyn reservoir (Southern Poland, Fig. 1) which receives the tannery contaminated wastewaters of the Dunajec river (about 300 small tanneries in the Nowy Targ region) and of other smaller creeks. The in situ exposure/sampling site was located in Maniowy Bay (Fig. 1) which is locally fed by a small creek collecting the effluent from a rural wastewater treatment plant (Fig. 1). Tanneries are also present in the region of Maniowy, although only some of them confer their wastes to the wastewater treatment plant. More 
152

details on $\mathrm{Cr}$ contamination in the Czorsztyn reservoir can be found elsewhere (Dominik et al., 2007; Szalinska et al., 2010) and in part 1 of this study (Vignati et al., this issue).

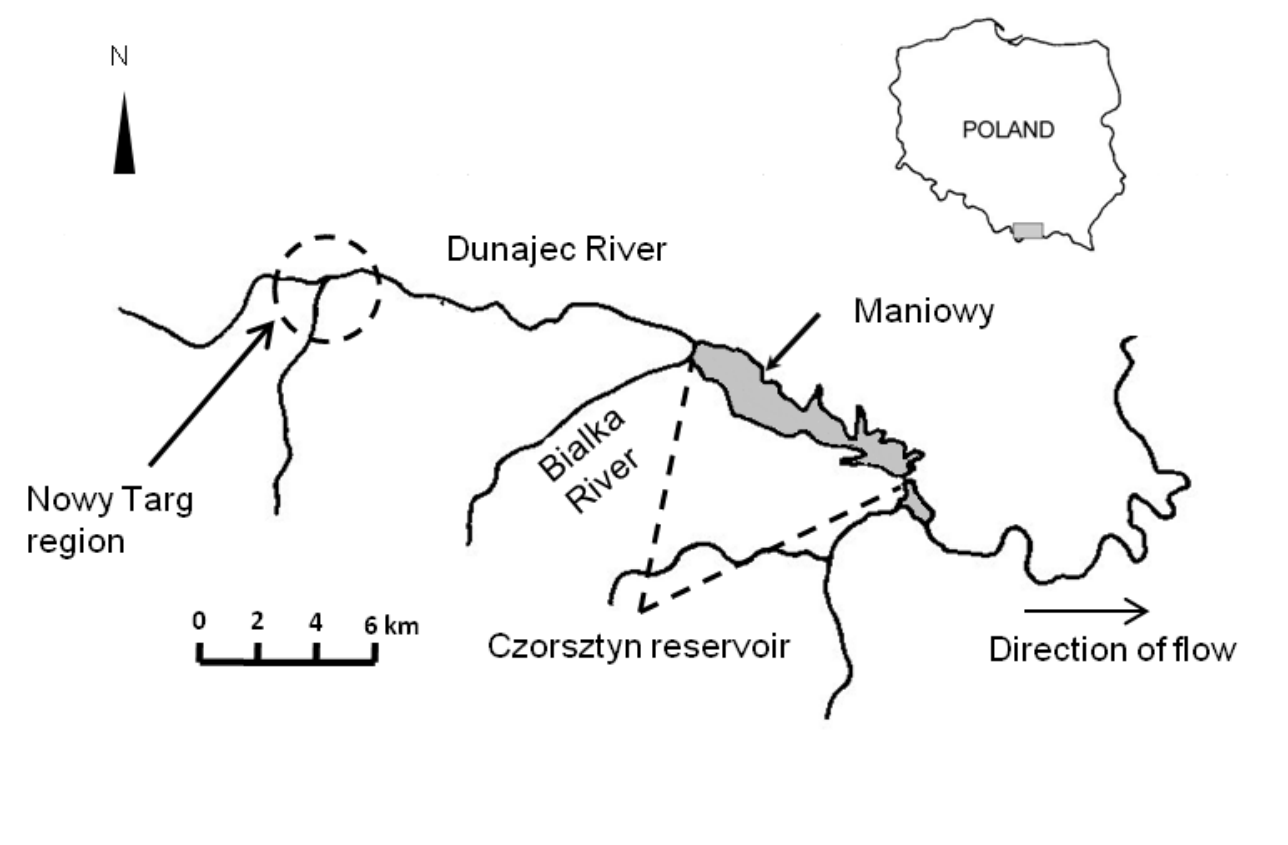

Figure 1. Study area (Czorsztyn reservoir; southern Poland) and location of the Maniowy Bay area where in situ exposures performed and samples collected for laboratory experiments. The Nowy Targ region, where the many artisanal tanneries are active, is also indicated.

\subsection{In situ bioaccumulation}

In situ exposure of $C$. riparius was carried out with a customized Sediment Water Interface Study System (S-WISS1.1) suitable for exposing surface deposit feeders to intact sediments for periods up to 4 days and allowing for food delivery to caged organisms during this period. Construction details and functioning were described in detail in Ferrari et al. (2014). Briefly, each exposure chamber consisted in a transparent polyvinyl chloride tube surmounted by a customized corer-head to deliver the chironomids, ensure water exchange between the 
exposure chambers and the surrounding waters and suspensions (150 $\mu \mathrm{m}$ Nitex mesh) and deliver the required food doses.

Twelve S-WISS1.1 were deployed at Maniowy (water depth approx. $3 \mathrm{~m}$ ) by scuba divers. In addition, twelve control cages consisting in 1-L high-density polyethylene (HDPE), largemouth bottles containing clean sand and partly covered with $150 \mu \mathrm{m}$ Nitex mesh (Ferrari et al., 2014) to ensure water exchange were deployed in the vicinity of the S-WISS1.1 devices. Food delivery in the control cages was also ensured by adopting the design described in Ferrari et al. (2014). At $\mathrm{t}=0,20$ individuals of $C$. riparius $\left(4^{\text {th }}\right.$ instar larvae) were introduced into each exposure system (i.e. S-WISS1.1 and control cages). Food doses (1 mg Tetramin® per individual) were delivered immediately after deployment and then every 24 hours until the end of the exposure period (4 days). At $t=24,48,72$, and 96 hours, three exposure chambers and three control cages were randomly recovered.

Upon arrival at the laboratory, each S-WISS1.1 was opened and an aliquot of the overlying water was sampled, filtered at $1.2 \mu \mathrm{m}$, acidified to $1 \% \mathrm{v} / \mathrm{v}$ with concentrated (65\%) Suprapur $\mathrm{HNO}_{3}$ and stored in a polypropylene (PP) container at $4{ }^{\circ} \mathrm{C}$ pending $\mathrm{Cr}$ analysis. After siphoning-off the remaining water, an aliquot of the top layer of sediments $(0-0.5 \mathrm{~cm})$ was gently scraped with a plastic spatula, passed through a $1 \mathrm{~mm}$ sieve to remove debris, and possibly chironomids, and stored in a PP container at $-22{ }^{\circ} \mathrm{C}$ pending $\mathrm{Cr}$ analysis.

The sediment from the surface layer was chosen because it represents the most relevant exposure zone for surface deposit-feeders such as C. riparius (Rasmussen, 1984). The whole sediment core was then sieved $(500 \mu \mathrm{m})$ to recover surviving chironomids. No indigenous chironomids were found in the cores. Recovered organisms were rinsed with site water and placed for $5 \mathrm{~min}$ in trays filled with ultrapure water (MilliQ water, Millipore), followed by 10 min in $1 \mathrm{mM}$ EDTA, and additional $5 \mathrm{~min}$ in ultrapure water. After gently blotting with paper towels, each larva was measured using a digital image analysis system and organisms were 
pooled and conditioned for $\mathrm{Cr}$ analysis (see Ferrari et al., 2014 for more details). Individual length ( $\mathrm{n}=20)$ and initial $\mathrm{Cr}$ body residue of unexposed larvae ( 2 pools of 30 individuals) were determined at the start of each experiment.

\subsection{Laboratory bioaccumulation studies}

Laboratory experiments were set up using both field-collected sediments from Maniowy and clean sand. Maniowy sediments were collected with an Ekman grab during the deployment of the in situ test systems and stored at $4{ }^{\circ} \mathrm{C}$. Upon return to the laboratory, the overlying water was decanted and sediment were sieved at $1 \mathrm{~mm}$ and homogenised on the day before the start of the tests. Sediments (clean sand for controls) were transferred into 1-L HDPE bottles analogous to those used for the control cages in the field experiment and covered with filtered $(1.2 \mu \mathrm{m})$ Lake Geneva water at a minimum ratio of 1:4. The following day, 20 individuals of $C$. riparius were introduced into each exposure bottle and fed daily as the chironomids exposed in situ. Young second instar larvae were used for performing a 7-day bioaccumulation tests, while young fourth instar larvae were used for a 4-day tests.

All exposures were performed in triplicate at $21^{\circ} \mathrm{C}$ under a $16: 8$-h light-dark photoperiod and light intensity of 500 lux. Air was continuously bubbled into each beaker during the test taking care to avoid sediment resuspension. The water level was controlled daily in each beaker and adjusted with deionised water if necessary. Larvae were fed daily ad libitum with $0.6 \mathrm{mg}$ of commercial food (Tetramin®) per individual (Péry et al., 2002).

For the 4-day bioaccumulation tests, organisms were retrieved and handled for length measurement (i.e. each individual) and $\mathrm{Cr}$ content (i.e. pool of 20 individuals) as in situ exposed ones at day 1, 2, 3 and 4. For the 7-day exposure tests, organisms were retrieved and handled in the same way only at the end of the test. For each exposure condition, the surface layer sediments (or sand) were sampled for total $\mathrm{Cr}$ analysis. 


\subsection{Chemical analyses}

Chromium concentration in sediments and chironomids were assayed using the same

217 methodologies described in Vignati et al. (this issue). Total $\mathrm{Cr}$ concentrations in overlying waters (filtered at $1.2 \mu \mathrm{m}$ ) in S-WISS1.1 cages were determined by ICP-MS, while Cr(VI) levels were determined by catalytic adsorptive stripping voltammetry (Bobrowski et al., 2012). Accumulation by chironomids was corrected for gut sediment content according to (Hare et al., 1989) assuming that ingested sediments represented 6\% of the total weight of individual organisms (see Ferrari et al., 2014). For quality control procedures, reference materials LKSD-4 (Lynch, 1990) and WQB3 (NRC, Canada) were used for sediments, TORT-2 (NRC, Canada) for biological material and SLRS3 (NRC, Canada) and 1643e (NIST) for waters. Reference material 1643e was analyzed following a 10-fold dilution.

\subsection{Modelling of bioaccumulation}

According to the biodynamic bioaccumulation modelling - DYMBAM (Baumann and Fisher, 2011; Wang et al., 1997), accumulation of a contaminant by living organism can be described by the following formula:

$$
C_{\text {biota }}=\frac{k_{u} \cdot C_{w}}{k_{e w}+g}+\frac{A E \cdot I R \cdot C_{s}}{k_{e s}+g}
$$

where $C_{\text {biota }}$ is the concentration accumulated by organisms (in $\mu \mathrm{g} \mathrm{g}^{-1}$ ), $k_{u}$ is the uptake rate constant from the dissolved phase (in $\mathrm{L} \mathrm{g}^{-1} \mathrm{~d}^{-1}$ ), $C_{w}$ is the concentration in the water phase (filtered water, in $\mu \mathrm{g} \mathrm{L}^{-1}$ ), $k_{e w}$ and $k_{e s}$ are the efflux rate constants following uptake from the dissolved phase and from food (sediments in the case of deposit feeders; both in $\mathrm{d}^{-1}$ ), $A E$ is the 
assimilation efficiency (in \% total content) from food (i.e., sediment), $I R$ is the food ingestion rate (in $\mathrm{g} \mathrm{g}^{-1} \mathrm{~d}^{-1}$ ), $C_{s}$ is the concentration in sediments (in $\mu \mathrm{g} \mathrm{g}^{-1}$ ) and $g$ is the growth rate constant (in $\left.\mathrm{d}^{-1}\right)$.

Although model parameters were not available for C. riparius, first-order estimates of expected $\mathrm{Cr}$ accumulation were obtained based on the following considerations. Accumulation from the aqueous phase was neglected considering that sediments should be the dominant route of contaminant uptake for chironomids (Dabrin et al., 2012; De Jonge et al., 2010; Martin et al., 2008). An ingestion rate of $0.325 \mathrm{~g} \mathrm{~g}^{-1} \mathrm{~d}^{-1}$ estimated for $C$. riparius at 10 ${ }^{\circ} \mathrm{C}$ (Bervoets et al., 2003) was adopted and corrected for the field/laboratory temperature of this study $\left(21{ }^{\circ} \mathrm{C}\right)$ as described in the supporting information. A value of $0.1 \%$, determined using the biomimetic approach described in the companion paper (Vignati et al., this issue), was used for the $\mathrm{AE}$ of $\mathrm{Cr}$ from Maniowy sediments. Estimation of the organisms' growth rate constant $(g)$ was performed by fitting an exponential curve to the plot of weight of individual chironomids' larvae vs. time (Fig. S2). Finally, the $k_{\mathrm{es}}$ constant was neglected considering that literature values for $\mathrm{Cr}$ egestion by various organisms (Baumann and Fisher, 2011; Roditi and Fisher, 1999; Wang et al., 1997) did not exceed $0.019 \mathrm{~d}^{-1}$ and thus were 4 to 8 -fold lower than the growth rates calculated from our experimental data (Fig. S2). The conclusions of the present study would not have been altered by considering $k_{\mathrm{es}}$ in model calculations (see section 4.1) and this approach was preferred to the arbitrary choice of parameters derived for organisms other than C. riparius.

\subsection{Statistics}

Data were analyzed using Student's t-test, analysis of variance (one-way ANOVA followed by post-hoc Tukey's HSD test) and linear regression. All data were checked for normality and homogeneity of variance by the Shapiro-Wilk test and the Bartlett test, 
respectively. If conditions for ANOVA were not fulfilled, the data were log-transformed and reanalysed. For all statistical tests, the significance level was set at 0.05 and calculations were performed using the software package $\mathrm{R}$ (v 2.9.0).

\section{Results}

\subsection{Quality control}

Figures of merit and overall accuracy of $\mathrm{Cr}$ analysis in aqueous matrices were analogous to those reported in Vignati et al. (this issue). Percentage Cr recovery from LKSD-4 was about $120 \%$ when based on the concentrated $\mathrm{HNO}_{3} /$ concentrated $\mathrm{HCl}$ extractable fraction $(21 \pm 2 \mu \mathrm{g}$ $\left.\mathrm{g}^{-1}\right)$ and $75 \%$ when based on total $\mathrm{Cr}$ content determined by X-ray diffraction $\left(33 \pm 6 \mu \mathrm{g} \mathrm{g}^{-1}\right.$; $\mathrm{n}=2$ in both cases). For WQB3, measured Cr concentrations were $96 \pm 8 \%(\mathrm{n}=5)$ of the indicative value of $119 \mu \mathrm{g} \mathrm{g}^{-1}$. Triplicate analyses of sediment subsamples from selected cages agreed to $10 \%$ or better. Chromium recovery from TORT-2 $\left(0.77 \pm 0.15 \mu \mathrm{g} \mathrm{g}^{-1}\right)$ was $96 \pm 3 \%$ $(n=3)$. Due to the insufficient biological material, no replicate analyses of exposed chironomids were possible. However, the small standard deviation on the three replicates of TORT-2 material suggests an acceptable precision in the digestion of the biological material.

\subsection{Bioaccumulation under in situ and laboratory conditions}

Chromium concentrations in sediments recovered inside the S-WISS1.1 units were homogeneous among the cages and across the four days of exposure $\left(325 \pm 35 \mu \mathrm{g} \mathrm{g}^{-1}, \mathrm{n}=11\right)$. The $\mathrm{Cr}$ content of homogenised sediments from Maniowy used for the laboratory exposures was uniform $\left(150 \pm 14 \mu \mathrm{g} \mathrm{g}^{-1}\right.$ d.w., $\left.\mathrm{n}=12\right)$, albeit about half of that measured in the sediment recovered from in situ cages. Chromium levels in sand used for control exposures were $1.2 \pm 0.5 \mu \mathrm{g} \mathrm{g}^{-1}(\mathrm{n}=12)$ in the field and $0.8 \pm 0.1 \mu \mathrm{g} \mathrm{g}^{-1}(\mathrm{n}=12)$ in the laboratory (Fig. S3). 
Bioaccumulation kinetic patterns in chironomids exposed to Maniowy sediments were similar for laboratory and in situ exposures, with a marked increase over the first day followed by a plateau in accumulated Cr levels. Daily and overall variability were however higher for organisms exposed in situ (Fig. 2).
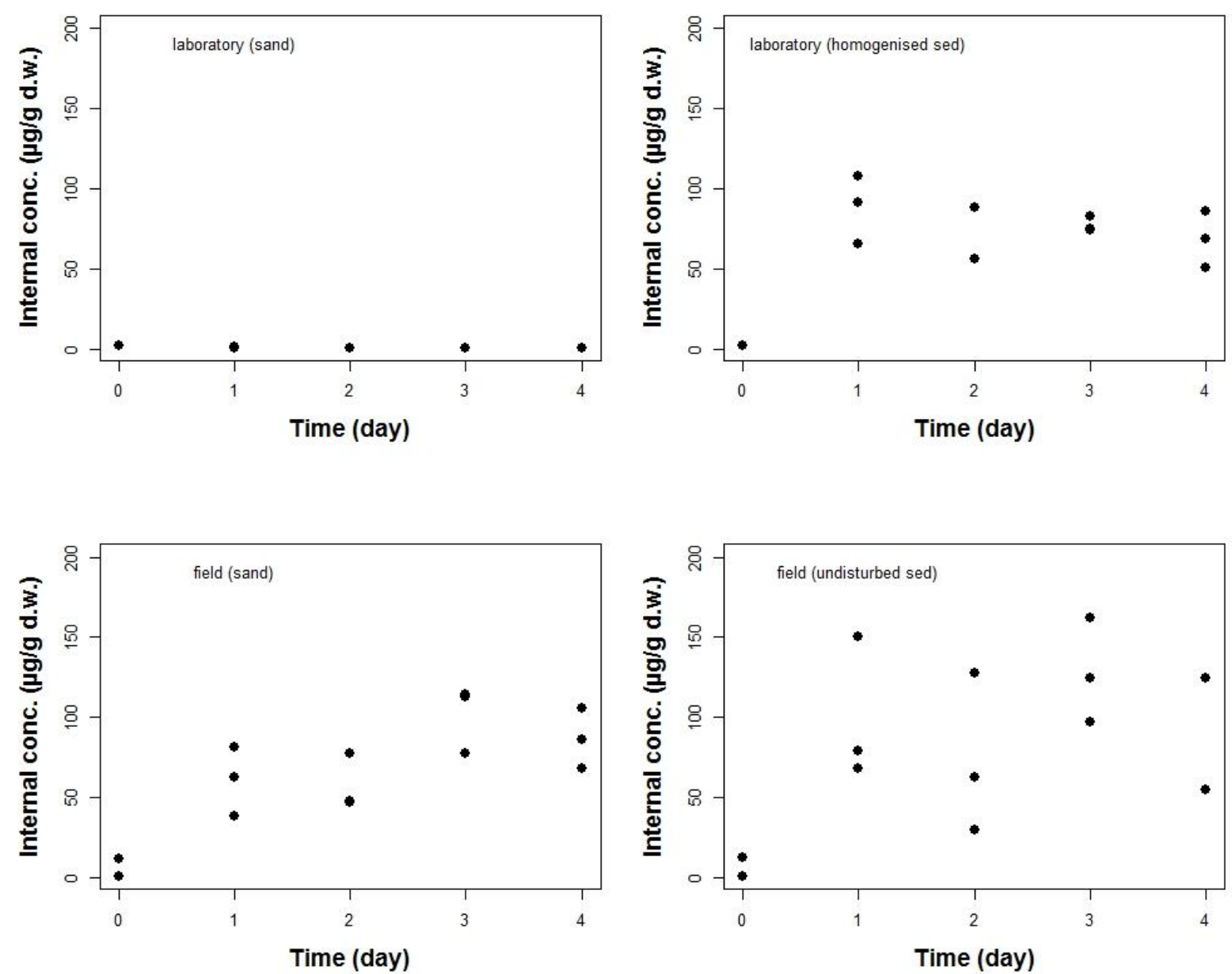

291

Figure 2. Cr accumulation vs. time in Chironomus riparius larvae exposed to sand and sediment in experiments performed in situ (Maniowy Bay, June 2007) and in the laboratory using sand and field collected sediment. In all experiments, each point represents the measure of $\mathrm{Cr}$ internal concentration obtained for the pooled organisms retrieved in each exposure system. Concentrations in chironomids were gut corrected according to Hare et al. (1989). 
At plateau (days 2-4), chironomids exposed in the laboratory to homogenised sediments

299 from Maniowy accumulated an average $\mathrm{Cr}$ concentration of $78 \pm 16 \mu \mathrm{g} \mathrm{g}^{-1} \quad(\mathrm{n}=12)$, comparable

to the concentration of $98 \pm 43 \mu \mathrm{g} \mathrm{g}^{-1}(\mathrm{n}=11)$ measured in chironomids exposed in situ to

301

302

303

304

305

306

307 undisturbed field sediments using the S-WISS1.1 system. At the opposite, bioaccumulation kinetic patterns in chironomids exposed to clean sand showed a marked difference between the laboratory and in situ exposures. Indeed, no increase in $\mathrm{Cr}$ concentration was observed during laboratory exposures with control chironomids accumulating less than $1 \mu \mathrm{g} \mathrm{g}^{-1}$ (Fig. 2). On the contrary, chironomids exposed in cages filled with clean sand but placed on the reservoir bottom close to the S-WISS1.1 devices accumulated an average of $77 \pm 25 \mu \mathrm{g} \mathrm{Cr} \mathrm{g}^{-1}$ $(n=12)$. This value is comparable to the concentrations obtained for chironomids exposed to the Maniowy sediments, whether in laboratory experiments or after in situ exposures (Fig. 2).

Results obtained by exposing $4^{\text {th }}$ instar larvae in situ or in the laboratory also compared favourably with those of $2^{\text {nd }}$ instar larvae exposed for 7 days to homogenised sediments in the laboratory (Fig. 3). Indeed, three days after the start of any type of exposure protocol using young $4^{\text {th }}$ instar larvae (see sections 2.2 and 2.3), all larvae were 9 days old after hatching (Fig. S1). Thus, $4^{\text {th }}$ instar larvae exposed over 3 days to sediments in situ or in the laboratory were as old as $4^{\text {th }}$ instar larvae remaining at the end of the 7-day bioaccumulation test in the laboratory which was started with young $2^{\text {nd }}$ instar larvae (Fig. S1).

For 3 days exposures of $4^{\text {th }}$ instar larvae, $\mathrm{Cr}$ concentrations in organisms exposed to sediment and sand (i.e., controls) were $128 \pm 33 \mu \mathrm{g} \mathrm{g}^{-1}$ vs. $101 \pm 21 \mu \mathrm{g} \mathrm{g}^{-1}$ for in situ experiments and $77 \pm 5 \mu \mathrm{g} \mathrm{g}^{-1}$ vs. $0.42 \pm 0.07 \mu \mathrm{g} \mathrm{g}^{-1}$ for laboratory experiments (Fig. 3). A statistically significant difference in $\mathrm{Cr}$ accumulation (Tukey HDS test on log-transformed data, $\mathrm{p}<0.05)$ existed between controls and exposed chironomids only in laboratory experiments. Despite the variability in the $\mathrm{Cr}$ content of sediment substrates (Fig. S3), $\mathrm{Cr}$ accumulation was not significantly different between organisms caged in the field (control 
and exposed) and organisms exposed to homogenised Maniowy sediments in the laboratory

324 (Tukey HDS test on log-transformed data, $\mathrm{p}>0.05$ ). For 7 days experiments started using $2^{\text {nd }}$

325 instar larvae, measured $\mathrm{Cr}$ accumulation at day 7 was $66 \pm 8 \mu \mathrm{g} \mathrm{g}^{-1}$ and $0.67 \pm 0.17 \mu \mathrm{g} \mathrm{g}^{-1}$ in organisms exposed to sediments and control sand, respectively. Chromium accumulation in $2^{\text {nd }}$ instar larvae exposed to Maniowy sediment for 7 days was significantly lower than in $4^{\text {th }}$ instar larvae exposed for 3 days to undisturbed field sediments (Tukey HDS test on logtransformed data, $\mathrm{p}<0.05)$, but did not show significant differences with other experimental conditions (Fig. 3).

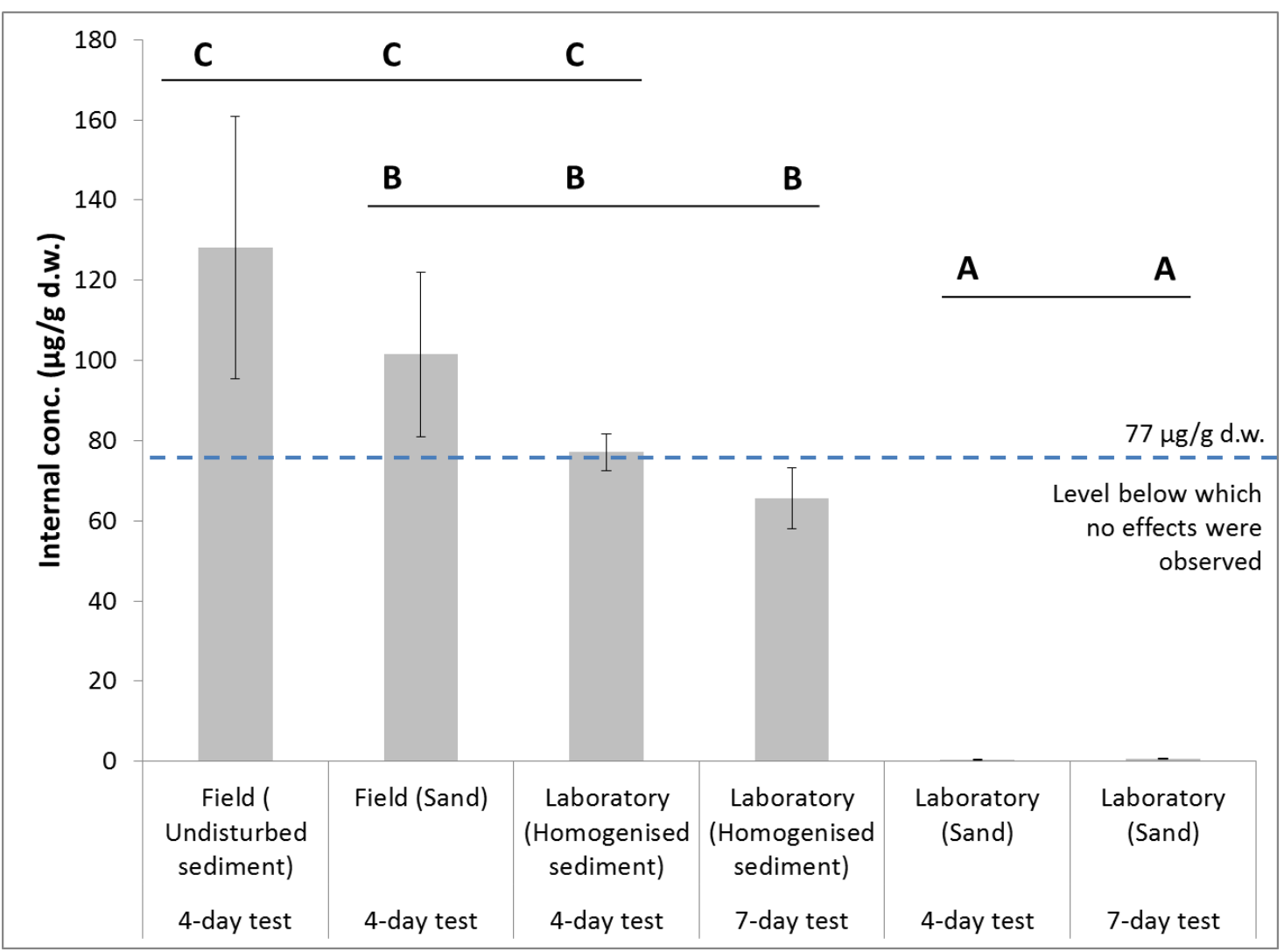

Figure 3. Cr accumulation at day 3 in Chironomus riparius larvae exposed to sand and sediment in experiments performed in situ (Maniowy Bay, June 2007) and in the laboratory using field collected material. The 4-day tests were initiated with young fourth instar larvae, while the 7-day tests were initiated with young second instar larvae. Error bars represent 1 standard deviation $(n=3)$. Internal concentrations that do not share the same letter 
are significantly different (ANOVA followed by post-hoc Tukey's HSD test, $\mathrm{p}<0.05$ ). The dotted line symbolizes the level below which no effects were observed by considering the results obtained for growth rates (see Fig. S2).

\subsection{Modelling chromium bioaccumulation via sediment ingestion}

The modelled $\mathrm{Cr}$ accumulation via sediment ingestion by $C$. riparius exposed to Maniowy sediments did not exceed $1 \mathrm{\mu g} \mathrm{g}^{-1}$ for neither in situ nor laboratory exposures. These values were $1 \%$ (or less) of measured ones and strongly underestimated the actual Cr burden in both scenarios (Fig. 4a, 4b). Because the biomimetic approach used to derive the AE of $0.1 \%$ employed in model calculation (see section 2.5) may overlook other factors resulting in higher assimilation efficiencies (Vignati et al., this issue), additional model calculations were performed using AE values of 1, 2 and 5\%. These AEs were reported in studies on $\mathrm{Cr}$ uptake by various organisms and from different substrates including sediments and algae (Baumann and Fisher, 2011; Roditi and Fisher, 1999; Wang et al., 1997). Even for the maximum AE value of 5\%, modelled concentrations were 40-60\% lower than the measured ones (Figure 4a, b).

Chironomids exposed to clean sand in laboratory experiments did not show any appreciable $\mathrm{Cr}$ bioaccumulation suggesting that neither the ingestion of sand substrate (in field controls) nor the added Tetramin® food (all experimental conditions) contributed to the observed $\mathrm{Cr}$ burdens. Measured $\mathrm{Cr}$ concentration in laboratory control chironomids actually decreased from $0.9 \pm 0.5 \mu \mathrm{g} \mathrm{g}^{-1}$ at day 1 to $0.4 \pm 0.06 \mu \mathrm{g} \mathrm{g}^{-1}$ at day 4 (data not shown). At $\mathrm{t}=0$, control chironomids had a $\mathrm{Cr}$ content of about $2 \mu \mathrm{g} \mathrm{g}^{-1}$, which was diluted by the ingestion of 'clean' food and by growth. On the other hand, measured concentration in field control organisms were comparable to those of organisms exposed to Maniowy sediments (Fig. 3). As it will be discussed in detail in section 4.1, we surmise that accumulation from freshly 

and also contributed the majority of accumulated $\mathrm{Cr}$ to organisms exposed in situ to unperturbed sediments.

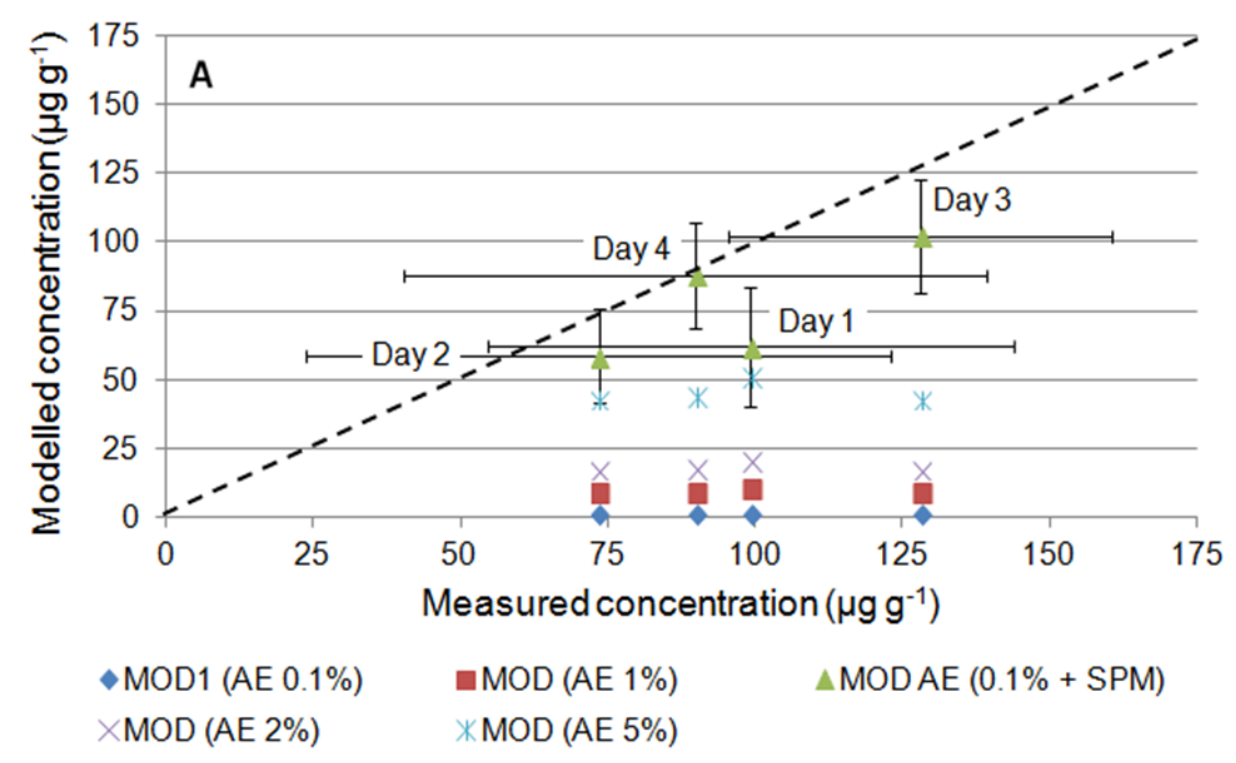

368 Figure 4. Comparison of measured vs. modelled $\mathrm{Cr}$ concentrations in Chironomus riparius exposed to

369 undisturbed Maniowy sediments in situ (S-WISS1.1 cages - panel A) and to homogenised Maniowy sediments

370 in the laboratory (panel B). All values are in $\mu \mathrm{g} \mathrm{g}^{-1}$. MOD, modelled accumulation of Cr obtained using different

371 values for assimilation efficiency (AE) in formula 1; SPM, Cr accumulation in field control organisms (assumed

372 to originate from ingestion of freshly deposited Suspended Particulate Matter — see text for details); Correction 
'on site' and 'S-WISS', modelled accumulation using formula 1 and corrected for changes in bioavailability due to sediment manipulation according to Ferrari et al. (2014). The dashed lines show the theoretical 1:1 correspondence between modelled and measured concentrations.

\subsection{Effects on chironomids}

Survival of chironomids in laboratory controls was almost complete (19.6 \pm 0.7 individuals; $\mathrm{n}=12)$ over the 4 days of exposure and only slightly reduced (18.1 \pm 2.2 individuals, $n=12)$ for exposure to Maniowy sediments in the laboratory. Average survival in field controls was 16.3 \pm 3.7 individuals $(n=12)$; significantly higher than in organisms directly caged on sediments in situ $(9.8 \pm 2.7$ individuals, $\mathrm{n}=11)$. In this last case, no temporal trend in survival was observed.

The length of alive chironomids increased linearly and significantly $\left(\mathrm{R}^{2}>0.84, \mathrm{p}<0.0001\right)$ over time during the 4-day exposure both in the laboratory and in the field (Fig S2). In the laboratory, the growth rate of the chironomids exposed to sand was $0.1499 \pm 0.0054 \mathrm{~cm} \mathrm{~d}^{-1}$; not significantly different from the growth rate of $0.1421 \pm 0.0096 \mathrm{~cm} \mathrm{~d}^{-1}$ for the chironomids exposed to homogenised Maniowy sediments (ANOVA, p>0.05; Fig. S2). In the field, the growth rate of the chironomids exposed to sand $\left(0.1273 \pm 0.0065 \mathrm{~cm} \mathrm{~d}^{-1}\right)$ was significantly lower than the value obtained for control chironomids in the laboratory (ANOVA, $p=0.016$; Fig. S2). Growth rate further and significantly decreased to $0.092 \pm 0.0114 \mathrm{~cm} \mathrm{~d}^{-1}$ when the chironomids were exposed to the undisturbed sediments in situ using S-WISS1.1 (ANOVA, $\mathrm{p}=0.011 ;$ Fig. S2).

Concerning the 7-day bioaccumulation test, no significant effect was observed between controls and exposed chironomids. The lowest number of alive chironomids per beaker $(n=3)$ was 19 and 18 in controls and exposed organisms, respectively. The mean length at the end of 
exposure period was $1.01 \pm 0.02 \mathrm{~cm}$ in controls and $0.99 \pm 0.05 \mathrm{~cm}$ in chironomids exposed to the homogenised Maniowy sediment (t-test, $\mathrm{p}>0.05)$.

\section{Discussion}

\subsection{Importance of SPM as an additional exposure route to contaminants in the field}

The comparable $\mathrm{Cr}$ body burden in chironomids exposed in situ to undisturbed field sediments and to clean sand (Figs. 2 and 3) suggests the presence of an additional source of $\mathrm{Cr}$ for the organisms exposed in the field. The lower accumulation of $\mathrm{Cr}$ in chironomids exposed in the laboratory to homogenised sediments from Maniowy also supports the hypothesis that one (or more) additional source of $\mathrm{Cr}$ exists in the field. A possible contribution of Tetramin ${ }^{\circledR}$ to $\mathrm{Cr}$ bioaccumulation can be ruled out by the absence of $\mathrm{Cr}$ accumulation in control laboratory chironomids. We surmise that freshly deposited SPM entering the exposure cages can act as an important source of $\mathrm{Cr}$ to surface deposit feeders exposed in the field at the site of Maniowy. Besides the strong $\mathrm{Cr}$ accumulation by control chironomids exposed in situ, several observations collectively form a basis for evidence to support this hypothesis as detailed in the next paragraphs.

The lower accumulation by laboratory-exposed chironomids likely reflects the lower $\mathrm{Cr}$ concentration in homogenised sediments used for laboratory experiments compared with undisturbed field sediments (Fig. S3). The differences between homogenised and undisturbed (surface) sediments may be explained by the vertical decrease of $\mathrm{Cr}$ contamination in Maniowy sediments (Vignati et al., this issue). However, Ferrari et al. (2014) showed that, for sediments collected from the same site in Lake Geneva, Cr bioaccumulation was about 2- to 3-fold higher for chironomids exposed to homogenised sediments in the laboratory (sediment Cr content $25-30 \mu \mathrm{g} \mathrm{g}^{-1}$ ) than to undisturbed field sediments using S-WISS1.1 type cages (28-32 $\mu \mathrm{g} \mathrm{g}^{-1}$ of $\mathrm{Cr}$ ) or to homogenised sediments placed back in the field (27-32 $\mu \mathrm{g} \mathrm{g}^{-1}$ of 
Cr). In the study of Ferrari et al. (2014), temperature differences between laboratory $\left(21^{\circ} \mathrm{C}\right)$ and field $\left(15^{\circ} \mathrm{C}\right)$ alone could explain the observed differences. Sediment manipulation is also known to trigger a series of reactions that increase the bioavailability of sediment-bound contaminants (Vandegehuchte et al., 2013); in disagreement with our observations. Overall, these previous observations suggest that the higher accumulation of $\mathrm{Cr}$ in chironomids exposed in the field to undisturbed Maniowy sediments requires a supplementary source of bioavailable $\mathrm{Cr}$.

As observed in previous research on metal accumulation by chironomids (Dabrin et al., 2012; De Jonge et al., 2010; Martin et al., 2008), uptake of aqueous Cr species from overlying water and pore water is unlikely to be the main responsible for the observed bioaccumulation patterns in chironomids. In laboratory experiments, homogenized Maniowy sediments were covered with filtered water from Lake Geneva; which has a low $\mathrm{Cr}$ content (Edder et al., 2008; Kottelat, 2008) and should not contribute much to $\mathrm{Cr}$ accumulation. The occurrence of higher $\mathrm{Cr}$ body burdens in field control chironomids compared with organisms exposed to Maniowy sediments in the laboratory can therefore be considered indicative of $\mathrm{Cr}$ uptake from the overlying waters of Maniowy. This pattern was actually observed after 3 and 4 days of exposure (Figs. 2 and 3). However, differences in accumulated $\mathrm{Cr}$ concentrations were only $30 \%$ of the total body burdens, confirming the need for another source of $\mathrm{Cr}$ to explain the observed bioaccumulation in field controls. Furthermore, field control chironomids were exposed on a substrate of (initially) clean sand so that $\mathrm{Cr}$ uptake from pore water is unlikely to have contributed markedly to the elemental burden of these organisms.

Similar conclusions can be obtained by examining the total filterable $\mathrm{Cr}$ concentrations measured in overlying waters inside S-WISS1.1 cages (Table S1). These concentrations showed some variability between days $1+2\left(3.9 \pm 1.4 \mu \mathrm{g} \mathrm{L}^{-1} ; \mathrm{n}=6\right)$ and $3+4\left(35 \pm 29 \mu \mathrm{g} \mathrm{L}^{-1}\right.$; $\mathrm{n}=6$ ), but $\mathrm{Cr}$ accumulation by chironomids was not directly proportional to filterable $\mathrm{Cr}$ 
concentration inside the cages (Table S1). DGT measurements over 89 hours (slightly shorter than the 96 hours of chironomid exposure for logistic reasons) did not show any marked change in labile $\mathrm{Cr}$ in overlying or interstitial waters either (Fig. S4). The concentration of $\mathrm{Cr}(\mathrm{VI})$ measured in overlying waters of cages recovered on days 3 and 4 (Table S1) was $0.59 \pm 0.321 \mu \mathrm{g} \mathrm{L}^{-1}$ ( $\mathrm{n}=6$, range: $0.076-1.04 \mu \mathrm{g} \mathrm{L}^{-1}$ ) and comparable to the levels measured in pore waters recovered from sediment cores sampled in Maniowy (Vignati et al., this issue). Otherwise stated, caging did not markedly change $\mathrm{Cr}(\mathrm{VI})$ concentrations (which could have had consequences on $\mathrm{Cr}$ bioavailability) and DGT-labile $\mathrm{Cr}$, a proxy for bioavailable trivalent $\mathrm{Cr}$, remained constant during chironomids' exposure. Changes in $\mathrm{pH}$, conductivity and oxygen content within the S-WISS1.1 cages are also too limited (Ferrari et al., 2014) to result in significant increases of Cr oxidation from field sediments. Considering the egestion rate of Cr assimilated via the dietary pathway (i.e., the $k_{\text {es }}$ parameter in formula 1) would have further reduced the modelled $\mathrm{Cr}$ body burden. Overall, $\mathrm{Cr}$ uptake from freshly deposited SPM remains the hypothesis best supported by the available data to explain a) the observed $\mathrm{Cr}$ accumulation in field controls and $\mathrm{b}$ ) the higher $\mathrm{Cr}$ accumulation by chironomids exposed to Maniowy sediment in situ compared with laboratory exposures to homogenised sediment.

\subsection{A unifying framework for modelling, experimental results and field observations}

The hypothesis that ingestion of freshly deposited SPM (section 4.1) represents a significant route of $\mathrm{Cr}$ accumulation for chironomids exposed in situ allows to reconcile modelling calculations and experimental results to a great extent. Summing accumulation via SPM (i.e., the experimental values measured for field control cages) to the quantity of $\mathrm{Cr}$ accumulated from sediment ingestion (using an $\mathrm{AE}$ of $0.1 \%$ as determined by the biomimetic approach - see section 2.5) markedly improves the agreement between modelled and measured bioaccumulation for organisms exposed to Maniowy sediments in situ (Fig. 4a). 
472 With this procedure, modelled concentrations remain within $20 \%$ of measured ones for 2,3

473 and 4 days of exposure, again supporting the hypothesis that SPM is a major route of 474 exposure in field conditions. The $\pm 20 \%$ differences are within the possible contribution of $\mathrm{Cr}$ 475 uptake via the aqueous route; as in indicated by the comparison between laboratory exposure 476 to Maniowy sediments and in situ control cages (see section 4.1).

477 On the other hand, a contribution of freshly deposited SPM to Cr accumulation cannot be invoked to reduce the discrepancies between modelled and experimental $\mathrm{Cr}$ concentrations for chironomids exposed to Maniowy sediments in the laboratory (Fig. 4b). Accumulation via aqueous exposure, if any, would not lead to a better agreement between modelled and experimental results either (see sections 3.3 and 4.1). It is however possible that sediment manipulation during the setup of laboratory exposure may increase $\mathrm{Cr}$ bioavailability for chironomids. In the case of the Vidy Bay (a polluted bay in Lake Geneva, Switzerland/France), Ferrari et al. (2014) reported that $\mathrm{Cr}$ bioaccumulation by $C$. riparius in the laboratory was about twice than in specimen of the same species exposed in the field (SWISS1.1 cages). Chromium accumulation in the laboratory was even 4-5 times higher than in organisms exposed on site in cages containing the same homogenised field sediments used in the laboratory. However, including a correction factor of 2 (in situ vs. laboratory) or 4.5 (on site vs. laboratory) into modelled bioaccumulation values for chironomids exposed to Maniowy sediment in the laboratory does not improve the agreement between observed and predicted results to any appreciable extent (Fig. 4b).

Another factor that may increase $\mathrm{Cr}$ bioavailability in laboratory exposure following 493 sediment manipulation is the association of $\mathrm{Cr}$ with $\mathrm{Fe} / \mathrm{Mn}$ oxides in Maniowy sediments 494 (Vignati et al., this issue). However, even assuming a $\mathrm{Cr}$ assimilation efficiency of 5\% for 495 chironomids exposed to Maniowy sediments in the laboratory, modelled results still remain about $15 \%$ of the measured accumulation at day 4 (Fig. $4 \mathrm{~b}$ ). One last option is that the 
development of an active Mn redox cycle at the sediment-water interface might have led to the formation of highly bioavailable $\mathrm{Cr}(\mathrm{VI})$ via oxidation of $\mathrm{Cr}(\mathrm{III})$ in the laboratory exposure beakers (Landrot et al., 2012). While the available experimental data do not allow to test this hypothesis, it appears that chromium bioaccumulation in the laboratory occurred to a different extent, and possibly via different routes, compared with real-field situations. Otherwise stated, the use of homogenised sediment to test for contaminant bioavailability may change the relative importance of the various exposure routes and lead to results not directly applicable in the field (Ferrari et al., 2014; Simpson and Batley, 2007; Wang et al., 2004).

It is also instructive to examine how well $\mathrm{Cr}$ accumulation by caged specimen of $C$. riparius can mimic $\mathrm{Cr}$ accumulation by indigenous chironomids. As already seen, consideration of Cr uptake via ingestion of freshly deposit SPM is necessary to reconcile DYMBAM calculations and experimentally measured accumulation for specimen of $C$. riparius exposed in situ to Maniowy sediment (Fig. 4a). However, even after accounting for the SPM route, the average accumulation of Cr by $C$. riparius inside S-WISS 1.1 cages $(98 \pm 23$ $\mu \mathrm{g} \mathrm{g}^{-1}$; arithmetic mean \pm one standard deviation for 4 days of exposure, $\mathrm{n}=11$ ) remains about 3 times lower than accumulation by indigenous chironomids recovered from Maniowy sediments during the same period $\left(315 \mu \mathrm{g} \mathrm{g}^{-1}\right.$ for the pool of chironomids sampling in June 2007; see Vignati et al., this issue). This difference may originate from individual indigenous chironomids weighing, on average, about 3.5 times as much as S-WISS1.1 exposed specimen on day 4 (1.43 vs. $0.388 \mathrm{mg})$. Larger individuals would ingest larger sediment quantities to meet their nutritional needs, while simultaneously accumulating more $\mathrm{Cr}$ from contaminated sediments. Furthermore, ingestion rate is inversely related to the organic matter content of a given sediment. Contrary to caged $C$. riparius, indigenous chironomids could not rely on Tetramin ${ }^{\circledR}$ as an additional source of $\mathrm{Cr}$-free carbon; which could again have led to higher ingestion rates and, eventually, higher Cr body burdens. These considerations equally apply to 
the ingestion of freshly deposited SPM and do not invalidate the hypothesis of SPM as the main $\mathrm{Cr}$ source to chironomids. Even if not performed in the same experimental conditions, it is interesting to note that Bervoets et al. (2004) found a very good agreement in Cr internal concentrations between caged and resident larvae, especially in the most contaminated sites.

\subsection{Effect of chromium on the growth of chironomids}

Individuals of $C$. riparius exposed to homogenised Maniowy sediments in the laboratory for 4 or 7 days did not exhibit higher mortality or reduced growth rate compared with control chironomids (section 3.4 and Fig. S2), indicating that Maniowy sediments were not toxic in standardized conditions. The absence of effects in laboratory exposures may be linked with sediment homogenisation. The Cr content of Maniowy sediments rapidly decreases below 5-6 cm (Vignati et al., this issue) because the Czorsztyn reservoir was flooded in 1997 and a thin layer of Cr-contaminated sediments overlies a relatively compact layer of former soil with low $\mathrm{Cr}$ content.

On the other hand, exposure to undisturbed sediments in the field resulted in reduced survival and growth rate compared with laboratory and field controls as well as with homogenised Maniowy sediments tested in the laboratory (section 3.4 and Fig. S2). During the in situ exposure period, water temperature in the field was around $21{ }^{\circ} \mathrm{C}$ and hence similar to the optimal temperature used for laboratory experiments. Moreover, chironomids have been daily fed ad libitum in all laboratory and in situ tests, thus preventing the impact of limiting food availability during in situ exposure. The differences between field controls and field exposed chironomids are therefore indicative of some kind of adverse effect of Maniowy sediments. Furthermore, the difference between field and laboratory controls also points to adverse effect linked to the presence of freshly deposited SPM which appears as an important route of exposure to $\mathrm{Cr}$ for chironomids during in situ experiments. 
When considering the quantity of $\mathrm{Cr}$ accumulated by specimen of $C$. riparius in relation to the growth results, it can be assumed that no effect on growth can be observed up to a total concentration of $77 \mu \mathrm{g} \mathrm{g}^{-1}$ (Fig. 3 and Fig. S2). This concentration could correspond to a Critical Body Residue (CBR). The CBR is the concentration of a chemical bioaccumulated in an organism above which ecotoxicity effects appear (McCarty and MacKay, 1993). The tentative CBR value of $77 \mu \mathrm{g} \mathrm{g}^{-1}$ agrees with the data of Méndez-Fernández et al. (2013) who determined a CBR of approx. $34 \mu \mathrm{g} \mathrm{g}^{-1}$ for Tubifex tubifex in tests with natural sediments spiked with $\mathrm{K}_{2} \mathrm{Cr}_{2} \mathrm{O}_{7}$. Upon entering living cells, $\mathrm{Cr}(\mathrm{VI})$ is rapidly converted to $\mathrm{Cr}$ (III) (Viti et al., 2014), so that a comparison of CBR for the two redox forms of $\mathrm{Cr}$ remains meaningful.

Recent studies have demonstrated that metal body burdens in relative resistant invertebrates such as chironomids can be used as predictors of ecological effects of metals on aquatic ecosystems. Bervoets et al. (2016) have linked threshold body burdens of metals in fourth instar larvae of indigenous Chironomus sp. to effects on resident macroinvertebrate communities. Depending on the descriptor chosen for the structure of the macroinvertebrate community, the threshold values ranged from 10 to $69 \mu \mathrm{g} \mathrm{g}^{-1} \mathrm{~d} . \mathrm{w}$. of $\mathrm{Cr}$ accumulated in chironomids. It is therefore possible that $\mathrm{Cr}$ contamination at Maniowy adversely affects sensitive taxa of macroinvertebrates. Furthermore, the tentative CBR value obtained for $C$. riparius in the present study suggests that $\mathrm{Cr}$ levels above $77 \mu \mathrm{g} \mathrm{g}^{-1}$ d.w. can also affect relatively pollution-tolerant organisms such as chironomids themselves. These findings are not at odds with the thresholds proposed by Bervoets et al. (2016) because laboratory-reared organisms are likely more sensitive than adapted local indigenous species.

However, the bioaccumulation results obtained in this study showed a large variability (Fig. 2) which hampers a clear definition of the actual CBR for $\mathrm{Cr}$ in $C$. riparius. Other studies also suggest that metals have toxic effects only when their uptake rate exceeds their combined rates of efflux and detoxification (Casado-Martinez et al., 2010) or the fraction of 
metabolically available metal increases (Rainbow, 2007). Knowledge of the subcellular fate of metals is therefore required to better understand the physiological processes underlying their bioaccumulation and toxicity. Such methods have been developed for larvae of chironomids (Gimbert et al., 2016; Péry et al., 2008) and will have to be considered to further clarify the metabolically available concentration of $\mathrm{Cr}$ that can affect the development of chironomids at different stages in real-field situations.

\section{Conclusions}

Comparable levels of $\mathrm{Cr}$ accumulation by specimen of Chironomus riparius exposed to undisturbed field sediments in situ and to clean sand on-site suggest that ingestion of freshly deposited SPM can be the main route of Cr accumulation by surface deposit feeders in real field conditions. This additional route of exposure is not accounted for in standardized laboratory experiments or, as yet, by biodynamic bioaccumulation modelling, so that both approaches will lead to an underestimation of $\mathrm{Cr}$ accumulation compared with field conditions. Changes in the bioavailability of sediment-bound $\mathrm{Cr}$ also seem to occur during sediment sampling and handling, with the correction of such experimental artefacts being far from straightforward. While both laboratory and in situ experiments provide evidence for the availability of $\mathrm{Cr}$ in aquatic system impacted by tannery wastewaters, in situ investigations appear necessary to obtain an adequate understanding of $\mathrm{Cr}$ bioavailability under real environmental conditions.

A tentative threshold of $\mathrm{Cr}$ accumulation for effects on the growth of C. riparius is proposed at $77 \mu \mathrm{g} \mathrm{g}^{-1} \mathrm{~d}$.w. Further studies using toxicokinetics approaches and subcellular fractionation methods are however required to refine the actual concentration of $\mathrm{Cr}$ linked to the biologically active sites and leading to adverse effects in these benthic organisms. Extrapolation from the model organism $C$. riparius to other species of indigenous 
597

598

599

600

601

602

603

604

605

606

607

608

609

610

611

612

613

614

615

616

617

618

619

620

chironomids also represents a future challenge to better link laboratory and in situ results with real field situations.

\section{Acknowledgements}

This research was supported by the Swiss National Fund (grants 200020-101844 and 200020117942). The authors express their sincerest thanks to Michal Krzyszkowski and the direction of the Niedzica Hydro-Electric Power Plant (Poland) for their precious cooperation. We are indebted to Mr. Przemek Kramin and Mr. Tomasz Smereczynski for handling of S-WISS1.1 in situ exposure systems in the Czorsztyn reservoir. We also thank our colleagues Vincent Chanudet, Régis Kottelat and Stephanie Jüstrich from the Institute F.-A. Forel for their help during field work.

\section{References}

Aharchaou I, Py JS, Cambier S, Loizeau JL, Cornelis G, Rousselle P, Battaglia E, Vignati DAL. 2018. Chromium hazard and risk assessment: New insights from a detailed speciation study in a standard test medium. Environmental Toxicology and Chemistry. 37(4):983-992.

Baumann Z, Fisher NS. 2011. Modeling metal bioaccumulation in a deposit-feeding polychaete from labile sediment fractions and from pore water. Science of The Total Environment. 409(13):2607-2615.

Bencheikh-Latmani R, Obraztsova A, Mackey MR, Ellisman MH, Tebo BM. 2007. Toxicity of Cr(III) to Shewanella sp. strain mr-4 during Cr(VI) reduction. Environ Sci Technol. 41:214-220. 
Bervoets L, De Bruyn L, Van Ginneken L, Blust R. 2003. Accumulation of ${ }^{137}$ Cs by larvae of the midge Chironomus riparius from sediment: effect of potassium. Environ Toxicol Chem. 22(7):1589-1596.

Bervoets L, De Jonge M, Blust R. 2016. Identification of threshold body burdens of metals for the protection of the aquatic ecological status using two benthic invertebrates. Environmental Pollution. 210(Supplement C):76-84.

Bervoets L, Meragalli G, De Cooman W, Goddeeris B, Blust R. 2004. Caged midge larvae (Chironomus riparius) for the assessment of metal bioaccumulation from sediment in situ. Environ Toxicol Chem. 23:443-454.

Bobrowski A, Kapturski P, Zarębski J, Dominik J, Vignati DAL. 2012. Catalytic adsorptive stripping voltammetric determination of chromium(VI) in overlying and interstitial waters isolated from sediments contaminated by tannery waste. Analytical Letters. 45(5-6):495-507.

Burton Jr GA, Rosen G, Chadwick DB, Greenberg MS, Taulbee WK, Lotufo GR, Reible DD. 2012. A sediment ecotoxicity assessment platform for in situ measures of chemistry, bioaccumulation and toxicity. Part 1: System description and proof of concept. Environmental Pollution. 162:449-456.

Casado-Martinez CM, Smith BD, Luoma SN, Rainbow PS. 2010. Metal toxicity in a sediment-dwelling polychaete: Threshold body concentrations or overwhelming accumulation rates? Environmental Pollution. 158(10):3071-3076.

Chatterjee N, Luo Z. 2010. Cr-(III)-organic compounds treatment causes genotoxicity and changes in DNA and protein level in Saccharomyces cerevisiae. Ecotoxicology. 19(4):593-603. 
Crane M, Burton GA, Culp JM, Greenberg MS, Munkittrick KR, Ribeiro R, Salazar MH, StJean SF. 2007. Review of aquatic in situ approaches for stressor and effect diagnosis. Integrated Environ Assess Manag. 3(2): 234-245.

Dabrin A, Durand CL, Garric J, Geffard O, Ferrari BJD, Coquery M. 2012. Coupling geochemical and biological approaches to assess the availability of cadmium in freshwater sediment. Science of The Total Environment. 424:308-315.

De Flora S, Bagnasco M, Serra D, Zanacchi P. 1990. Genotoxicity of chromium compounds. A review. Mutation Research/Reviews in Genetic Toxicology. 238(2):99-172.

De Jonge M, Blust R, Bervoets L. 2010. The relation between acid volatile sulfides (avs) and metal accumulation in aquatic invertebrates: Implications of feeding behavior and ecology. Environmental Pollution. 158(5):1381-1391.

Dominik J, Vignati DAL, Koukal B, Pereira de Abreu M-H, Kottelat R, Szalinska E, Bas B, Bobrowski A. 2007. Speciation and environmental fate of chromium in rivers contaminated with tannery effluents. Engineerig Life Science. 7:155-169.

Edder P, Ortelli D, Klein A, Ramseier S. 2008. Metals and organic micropollutants in Geneva Lake waters and sediments. Rapp. Comm. int. prot. eaux Léman contre pollut., Campagne 2007, 57-84.

Fairbrother A, Wenstel R, Sappington K, Wood W. 2007. Framework for metals risk assessment. Ecotoxicology and Environmental Safety. 68(2):145-227.

Ferrari BJD, Faburé J. 2017. Field assessment of reproduction-related traits of chironomids using a newly developed emergence platoform (e-board). Ecotoxicology and Environmental Safety. 137:186-193.

Ferrari BJD, Vignati DAL, Dominik J. 2014. Bioaccumulation kinetics and effects of sediment-bound contaminants on chironomids in deep waters: New insights using a low-disturbance in situ system. Environmental Technology. 35(4):456-469. 
Gimbert F, Geffard A, Guédron S, Dominik J, Ferrari BJD. 2016. Mercury tissue residue approach in Chironomus riparius: Involvement of toxicokinetics and comparison of subcellular fractionation methods. Aquatic Toxicology. 171:1-8.

Hare L, Campbell PGC, Tessier A, Belzile N. 1989. Gut sediment in a burrowing mayfly (Ephemeroptera, Hexagenia limbata): their contribution to animal trace element burderns, their removal, and the efficacy of a correction for their presence. Can J Fish Aquat Sci. 46:451-456.

Khwaja AR, Singh R, Tandon SN. 2001. Monitoring of Ganga water and sediments vis-à-vis tannery pollution at Kanpur (India): A case study. Environmental Monitoring and Assessment. 68(1):19-35.

Kottelat R. 2008. Caractérisation physico-chimique de microcosmes alimentés en continu et leur utilisation dans l'étude des voies d'exposition de Cd et Cr (III) chez "Daphnia magna". Terre et Environnement, Université de Genève; 73: 191 p.

Koukal B, Dominik J, Vignati D, Arpagaus P, Santiago S, Ouddane B, Benaabidate L. 2004. Assessment of water quality and toxicity of polluted rivers Fez and Sebou in the region of Fez (Morocco). Environ Poll. 131:163-172.

Kováčik J, Babula P, Hedbavny J, Kryštofová O, Provaznik I. 2015. Physiology and methodology of chromium toxicity using alga Scenedesmus quadricauda as model object. Chemosphere 120: 23-30.

Landrot G, Ginder-Vogel M, Livi K, Fitts JP, Sparks DL. 2012. Chromium(III) Oxidation by Three Poorly-Crystalline Manganese(IV) Oxides. 1. Chromium(III)-Oxidizing Capacity. Environmental Science \& Technology 46: 11594-11600.

Leghouchi E, Laib E, Guerbet M. 2009. Evaluation of chromium contamination in water, sediment and vegetation caused by the tannery of Jijel (Algeria): a case study. Environmental Monitoring and Assessment 153: 111-117. 
Lynch J. 1990. Provisional elemental composition values for eight new geochemical lake sediment and stream sediment reference materials LKSD-1, LKSD-2, LKSD-3, LKSD-4, STSD-1, STSD-2, STSD-3, STSD-4. Geostandards Newsletter 14: 153-167.

Martin S, Proulx I, Hare L. 2008. Explaining metal concentrations in sympatric chironomus species. Limnology and Oceanography 53(2):411-419.

McCarty LS, MacKay D. Enhancing ecotoxicological modeling and assessment. 1993. Environ. Sci. Technol. 27: 1719-1728.

Méndez-Fernández L, Martínez-Madrid M, Rodriguez P. 2013. Toxicity and critical body residues of $\mathrm{cd}, \mathrm{cu}$ and $\mathrm{cr}$ in the aquatic oligochaete tubifextubifex (müller) based on lethal and sublethal effects. Ecotoxicology 22(10): 1445-1460.

Michailova P, Petrova N, Sella G, Bovero S, Ramella L, Regoli F, Zelano V. 2001. Genotoxic effects of chromium onpolytene chromosomes of Chironomus riparius Meigen 1804 (Diptera, Chironomidae). Caryologia 54(1): 59-71.

Michailova P, Szarek-Gwiazda E, Kownacki A, Warchalowska-Sliwa E. 2011. Biodiversity of chironomidae (Diptera) and genome responses to trace metals in the environment. Pestydydy/Pesticides 1-4: 41-48.

Péry ARR, Geffard A, Conrad A, Mons R, Garric J. 2008. Assessing the risk of metal mixtures in contaminated sediments on Chironomus riparius based on cytosolic accumulation. Ecotoxicology and Environmental Safety 71: 869-873.

Péry ARR, Mons R, Flammarion P, Lagadic L, Garric J. 2002. A modeling approach to link food availability, growth, emergence, and reproduction for the midge Chironomus riparius. Environ. Toxicol. Chem. 21: 2507-2513.

Ponti B, Bettinetti R, Dossi C, Vignati DAL. 2014. How reliable are data for the ecotoxicity of trivalent chromium to daphnia magna? Environmental Toxicology and Chemistry 33(10): 2280-2287. 
Rainbow PS. 2007. Trace metal bioaccumulation: Models, metabolic availability and toxicity. Environment International 33: 576-582.

Rasmussen JB. 1984. Comparison of gut contents and assimilation efficiency of fourth instar larvae of two coexisting chironomids, Chironomus riparius Meigen and Glyptotendipes paripes (Edwards). Can. J. Zoology 62: 1022-1026.

Roditi HA, Fisher NS. 1999. Rates and routes of trace elements uptake in zebra mussel. Limnol. Oceanogr. 44: 1730-1749.

Simpson SL, Batley GE. 2007. Predicting metal toxicity in sediments: A critique of current approaches. Integrated Environmental Assessment and Management 3: 18-31.

Szalinska E, Dominik J, Vignati DAL, Bobrowski A, Bas B. 2010. Seasonal transport pattern of chromium(III and VI) in a stream receiving wastewater from tanneries. Applied Geochemistry 25: 116-122.

Vandegehuchte MB, Nguyen LTH, De Laender F, Muyssen BTA, Janssen CR. 2013. Whole sediment toxicity tests for metal risk assessments: on the importance of equilibration and test design to increase ecological relevance. Environmental Toxicology and Chemistry 32: 1048-1059.

Vignati DAL, Dominik J, Beye ML, Pettine M, Ferrari BJD. 2010. Chromium(VI) is more toxic than chromium(III) to freshwater algae: A paradigm to revise? Ecotoxicology and Environmental Safety 73: 743-749.

Vignati DAL, Ferrari BJD, Dominik J. 2007. Laboratory-to-field extrapolation in aquatic sciences. Environ. Sci. Technol. 41: 1067-1073.

Vignati DAL, Ferrari BJD, Roulier JL, Coquery M, Szalinska E, Bobrowski A, Czaplicka A, Dominik J. Chromium bioavailability in aquatic systems impacted by tannery wastewaters. Part 1: understanding chromium accumulation by indigenous chironomids. Science of The Total Environment ; this issue. 
751

752

753

754

755

756

757

758

759

760

761

762

763

764

765

766

767

768

Viti C, Marchi E, Decorosi F, Giovannetti L. 2014. Molecular mechanisms of Cr(VI) resistance in bacteria and fungi. FEMS Microbiology Reviews 38: 633-659.

Wang F, Goulet RR, Chapman PM. 2004. Testing sediment biological effects with the freshwater amphipod Hyalella azteca: the gap between laboratory and nature. Chemosphere 57: 1713-1724.

Wang W-X, Griscom SB, Fisher NS. 1997. Bioavailability of $\mathrm{Cr}(\mathrm{III})$ and $\mathrm{Cr}(\mathrm{VI})$ to marine mussels from solute and particulate pathways. Environ. Sci. Technol. 31: 603-611.

.

.

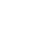




\section{Supporting information}

770

771

772

773

774

775

776

777

778

779

780

781

782

783

784

785

786

787

788

789

790

791

792

793

794

795

796

797

798

799

800

801

802

803

804

805

806

807

808

Chromium bioavailability in aquatic systems impacted by tannery wastewaters. Part 2:

new insights from laboratory and in situ testing with Chironomus riparius Meigen

(Diptera, Chrinomidae)

Ferrari B.J.D. ${ }^{\mathrm{a}, \mathrm{b}}$, Vignati D.AL. ${ }^{\mathrm{a}, \mathrm{c}}$, Roulier J.-L. ${ }^{\mathrm{d}}$, Coquery M. ${ }^{\mathrm{d}}$, Szalinska E. ${ }^{\mathrm{e}}$, Bobrowski A. ${ }^{\mathrm{f}}$, Czaplicka A. ${ }^{\mathrm{g}}$, Dominik, J.,

i) Department F.-A. Forel for Environmental and Aquatic Sciences, University of Geneva, Uni Carl Vogt, 66 boulevard Carl-Vogt CH-1211 Geneva, Switzerland

j) Swiss Centre for Applied Ecotoxicology Eawag-EPFL (Centre Ecotox), EPFL-ENACIIE-GE, Station 2, 1015 Lausanne, Switzerland

k) Université de Lorraine, CNRS, LIEC, F-57000 Metz, France

1) Irstea, UR RiverLy, centre de Lyon-Villeurbanne, F-69625 Villeurbanne, France

m) Department of Environment Protection, Faculty of Geology, Geophysics and Environmental Protection, AGH University of Science and Technology, $30 \mathrm{~A}$. Mickiewicza Av. , 30-059 Krakow, Poland.

n) Department of Building Materials Technology Faculty of Materials Science and Ceramics, AGH University of Science and Technology, 30 A. Mickiewicza Av. , 30-059 Krakow, Poland

o) Department of Water Supply, Sewerage and Environmental Monitoring, Cracow University of Technology, 24 Warszawska ul., 31-155 Krakow, Poland

p) Institute of Marine Science - National Research Council (ISMAR-CNR) Arsenale - Tesa 104, Castello 2737/F, 30122 Venice, Italy

*Corresponding Author: benoit.ferrari@centreecotox.ch

(1) 
810 Temperature correction for sediment ingestion rates was calculated according to the formula:

$811 \quad Q_{10}=\left(\frac{R_{2}}{R_{1}}\right)^{\left(\frac{10}{T_{2}-T_{1}}\right)}$

812 where: $\mathrm{Q}_{10}$ (dimensionless) is the rate of increase of a reaction for a 10 degrees temperature

813 increase (in ${ }^{\circ} \mathrm{C}$ or $\mathrm{K}$ ), $\mathrm{R}_{1}$ and $\mathrm{R}_{2}$ are the reaction rates at $\mathrm{T}_{1}$ and $\mathrm{T}_{2}$, respectively (with $\mathrm{T}_{1}<$

$814 \mathrm{~T}_{2}$ ). Web-based calculator (http://www.physiologyweb.com/calculators/q10_calculator.html )

815 was used to estimated temperature-adjusted sediment ingestion rates entering an arbitrary $\mathrm{Q}_{10}$

816 value of 2 in formula (A) (see below for the rationale behind this choice). Other input values

817 for formula A were the reference temperature of $10^{\circ} \mathrm{C}$ used by Bervoets et al. (2003), the

818 corresponding IR value of $0.325 \mathrm{~g} \mathrm{~g}-1 \mathrm{~d}-1$ for $\mathrm{C}$. riparius and the measured field and

819 laboratory temperature of $21^{\circ} \mathrm{C}$ for our study. A temperature corrected value of IR equal to

$820 \quad 0.697 \mathrm{~g}$ g-1 day-1 resulted from this calculations.

821 The Q10 factor of 2 was selected based on (Croteau et al., 2002; Gresens, 2001) who studied

822 the effect of temperature on $\mathrm{Cd}$ accumulation and sediment ingestion and digestion. It is

823 important to note that uncertainties exist as to the influence of temperature on sediment

824 ingestion rates and contaminant accumulation by chironomids In particular, the relationship

825 between temperature and sediment ingestion rate is not necessarily a monotonous one

826 (Gresens, 2001) and its determination would require experimental approaches outside the

827 scope of the present work. 
Table S1. Concentration of total Cr measured in overlying waters recovered inside each of the 830 three S-WISS cages on days 1, 2, 3, and 4; concentrations of hexavalent $\mathrm{Cr}$ in the same 831 waters; and concentration of total $\mathrm{Cr}$ in the chironomids exposed within each cage.

832

\begin{tabular}{|c|c|c|c|c|}
\hline Day & Replicate & $\begin{array}{l}\text { Water } \\
\text { Total Cr } \\
\left(\mu \mathrm{g} \mathrm{L}^{-1}\right)\end{array}$ & $\begin{array}{l}\operatorname{Cr}(\mathrm{VI}) \\
\left(\mu \mathrm{g} \mathrm{L}^{-1}\right)\end{array}$ & $\begin{array}{l}\text { Chironomids } \\
\text { Total } \mathrm{Cr}^{\mathrm{a}} \\
\left(\mu \mathrm{g} \mathrm{g}^{-1}\right) \text { d.w. }\end{array}$ \\
\hline 1 & 1 & 3.42 & n.a. & 68.1 \\
\hline 1 & 2 & 6.31 & n.a. & 150 \\
\hline 1 & 3 & 4.31 & n.a. & 79.2 \\
\hline 2 & 1 & 2.48 & n.a. & 29.9 \\
\hline 2 & 2 & 2.87 & n.a. & 63.0 \\
\hline 2 & 3 & 3.93 & n.a. & 127 \\
\hline 3 & 1 & 93.5 & 0.57 & 125 \\
\hline 3 & 2 & 26.1 & 0.61 & 162 \\
\hline 3 & 3 & 21.8 & 0.46 & 97.3 \\
\hline 4 & 1 & 23.8 & 1.04 & 54.9 \\
\hline 4 & 2 & 29.3 & 0.08 & n.a. \\
\hline 4 & 3 & 18.7 & 0.76 & 125 \\
\hline
\end{tabular}

a) Concentrations corrected for sediment content in the gut (see main text for details) 


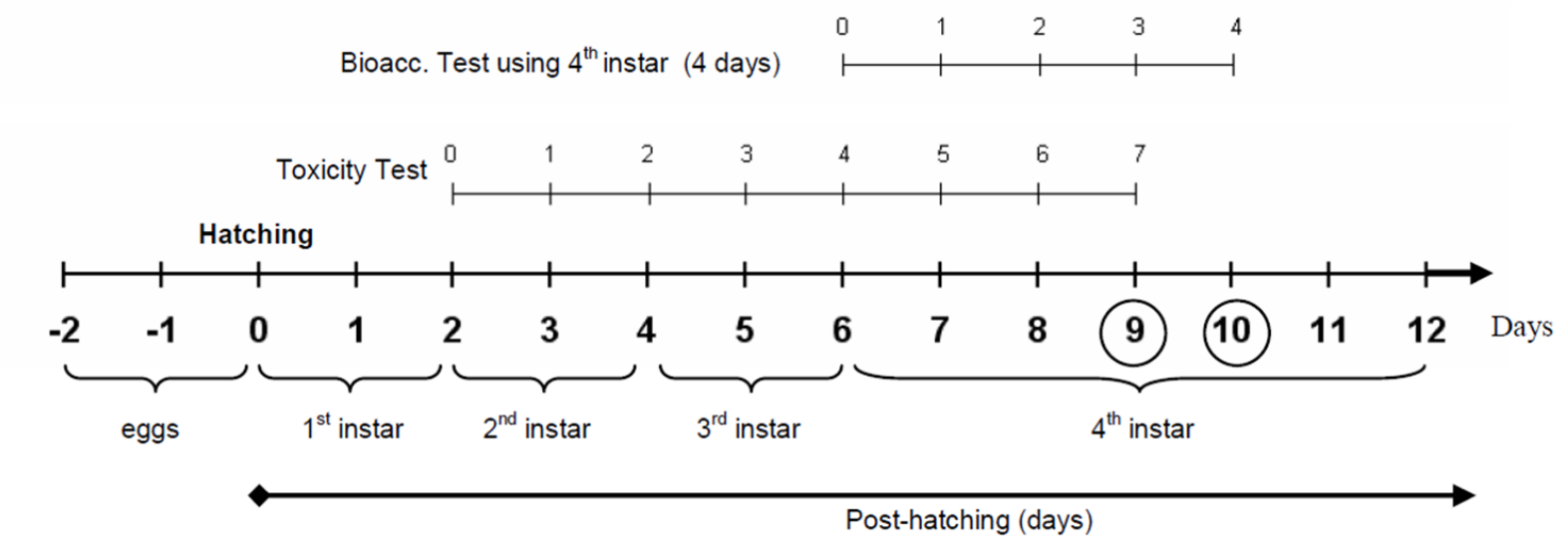

841

842 Figure S1. Chronological step for implementing the bioaccumulation and toxicity tests with 843 the non-biting midge larvae Chironomus riparius. For the present study, experiments were 844 started either with young second instar larvae (7 day laboratory tests) or with young fourth 845 instar larvae (4 day laboratory and in situ tests). Numbers correspond to the post-hatching 846 days needed to reach the end of the corresponding test. Note that $2^{\text {nd }}$ instar larvae used in 7847 day toxicity test and $4^{\text {th }}$ instar larvae used in bioaccumulation tests will have the same post848 hatching age at day 9. 


\section{Laboratory}

a)

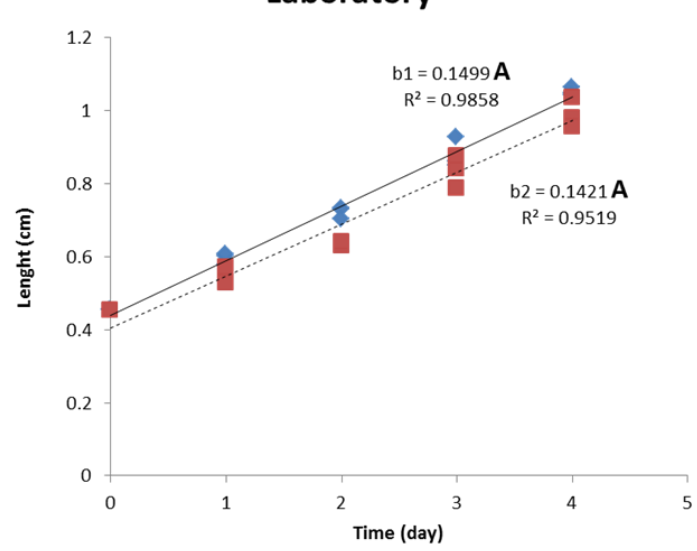

b)

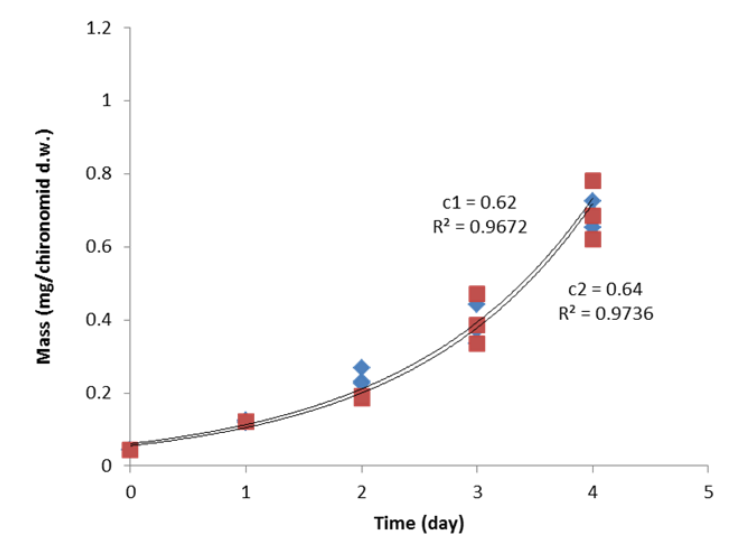

Field
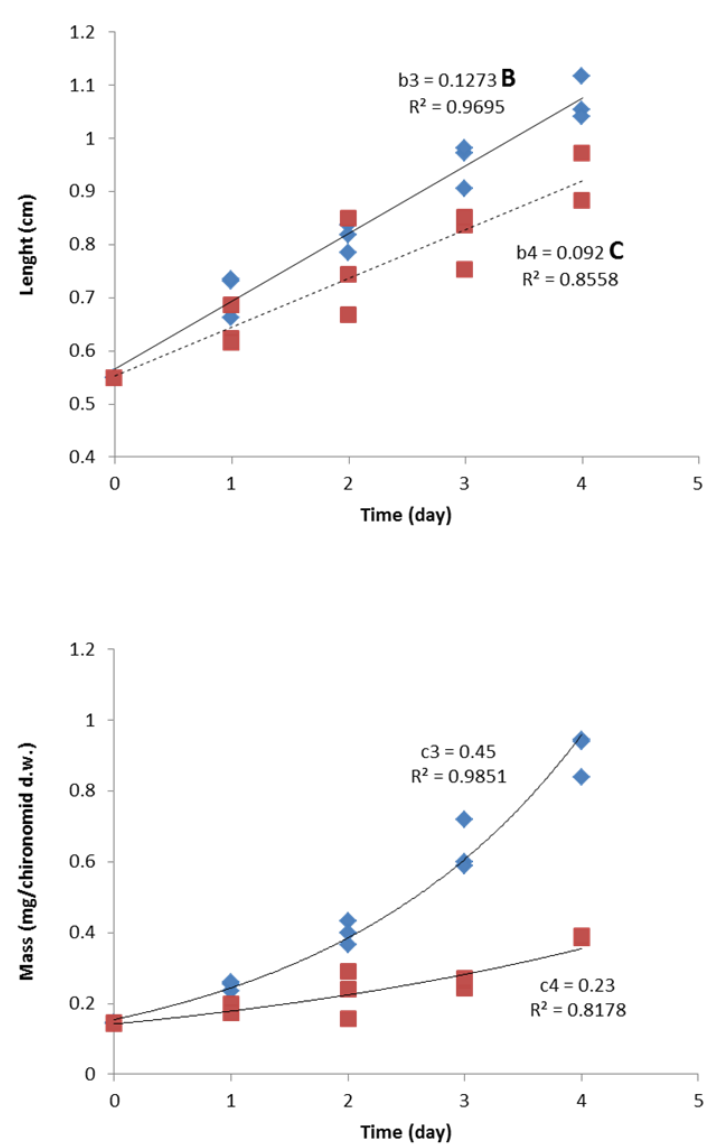

Figure S2. Evolution of the length (a) and weight (b) of $4^{\text {th }}$ instar Chironomus riparius larvae as a function of time in bioaccumulation experiments performed in the field (Maniowy Bay, June 2007) and in the laboratory using field collected material. Blue diamonds correspond to the measured responses of the chironomids exposed to the sand, while the red squares to the measured responses of those exposed to Maniowy sediments. In figures (a), each point represents the average of the lengths obtained by individually measuring live specimen recovered daily from each exposure batch. The lines represent linear regressions and parameters b1, b2, b3 and b4 their slopes (means \pm 1 s.e., in $\mathrm{cm} \mathrm{d}^{-1}$ ) defined as the representative growth rates $(\mathrm{g})$ for the different conditions. Slopes that do not share the same capital letter letter are significantly different (ANOVA, $\mathrm{p}<0.05$ ). In the figures (b), each point represents the weight of the pooled live chironomids. The lines represent exponential regressions and parameters $\mathrm{c} 1, \mathrm{c} 2, \mathrm{c} 3$ and $\mathrm{c} 4$ their slopes (means \pm 1 s.e., in $\mathrm{d}^{-1}$ ). $\mathrm{R}^{2}$ and $\mathrm{p}$ indicate the goodness-of-fit and the statistical significance of each fitted regression. 


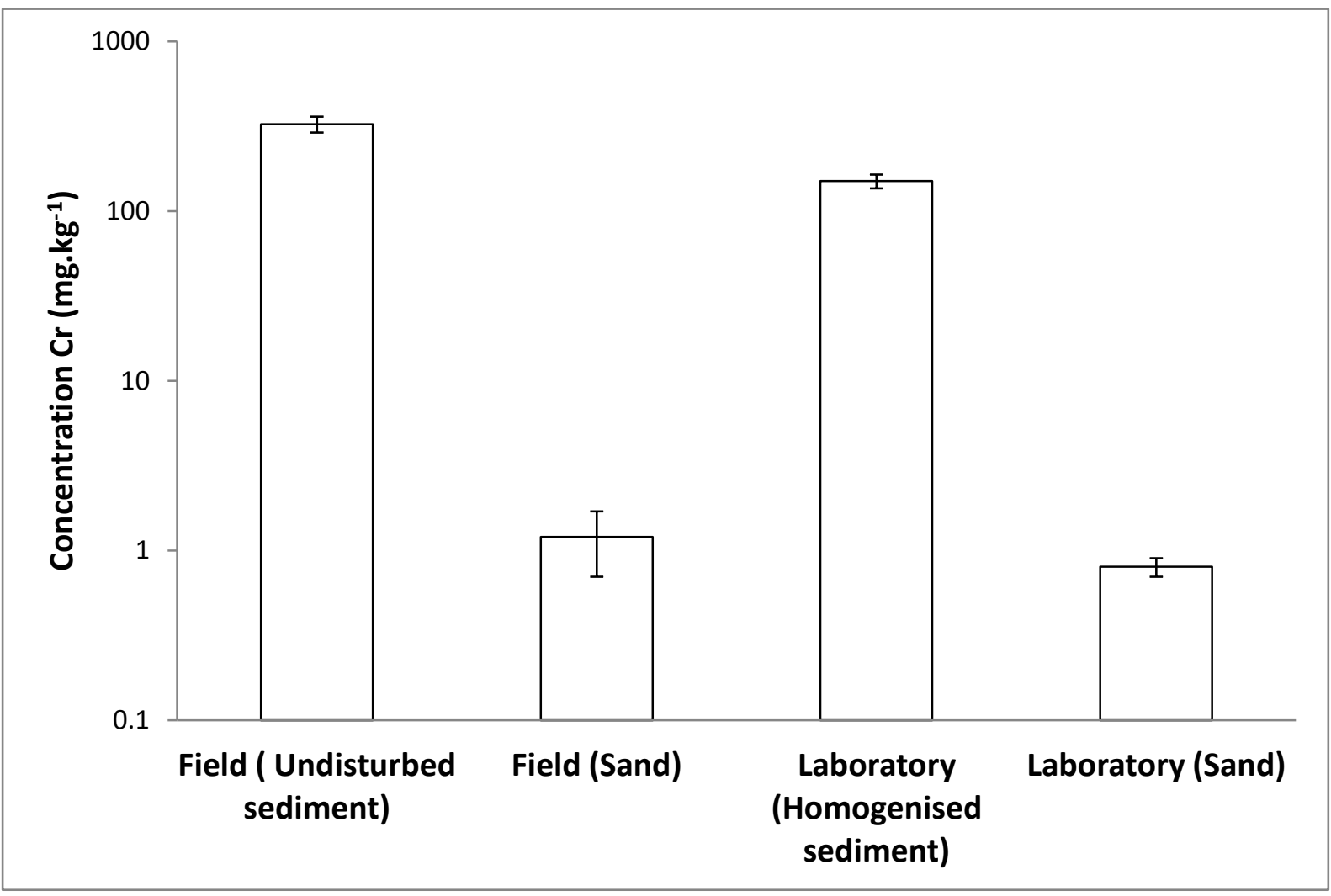

874 Figure S3. Total $\mathrm{Cr}$ concentrations ( $\mathrm{mg} \mathrm{kg}^{-1}$ d.w.) in sediments used in bioaccumulation 875 experiments performed in situ (Maniowy Bay, June 2007) and in the laboratory using field 876 collected material. Data are the arithmetic mean \pm one standard deviation $(\mathrm{n}=12)$ of $\mathrm{Cr}$ 877 concentration in each system of exposure retrieved during the 4 days of exposure in situ or in 878 the laboratory. Note the log scale on the vertical axis. 


\section{DGT-Cr concentration $\left(\mu \mathrm{g} \mathrm{L}^{-1}\right)$}

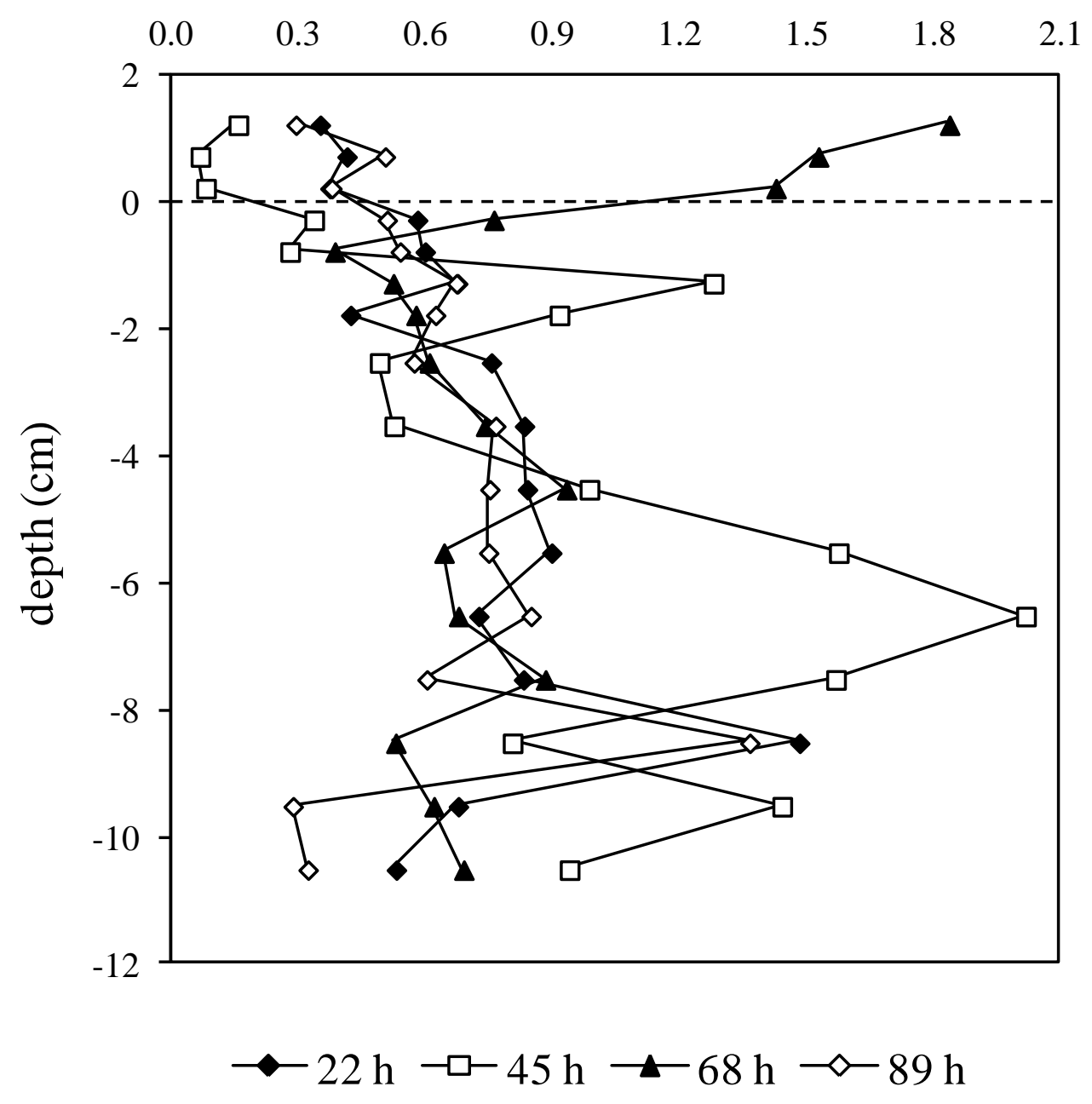

884

886 Figure S4. Temporal and vertical variability of DGT-labile Cr concentrations in interstitial 887 (negative depth values; in $\mathrm{cm}$ ) and overlying (positive depth values; in $\mathrm{cm}$ ) at Maniowy bay in 888 June 2007. Four different DGT probes were exposed at the same time and recovered after 22, 88945,68 and 89 hours of exposures. Exposure location was close to the cages for chironomids 890 and is assumed to be representative of $\mathrm{Cr}$ behaviour within the cages. 